\title{
Type 2 diabetes: remission in just a week
}

\author{
H. Yki-Järvinen
}

Received: 9 June 2011 / Accepted: 7 July 2011 /Published online: 9 August 2011

(C) Springer-Verlag 2011

Keywords Glucose · Insulin · Liver fat - NAFLD .

Remission - Type 2 diabetes . Weight loss

\section{Abbreviation \\ H-MRS Proton magnetic resonance spectroscopy}

We have learnt that type 2 diabetes can be prevented by maintaining a healthy lifestyle $[1,2]$. Such therapy is inexpensive and without side effects. Regarding patients with established type 2 diabetes, we often dream of a magic pill that would permanently solve the problem. We might perhaps view type 2 diabetes as a point of no return when we look at long-term data such as those provided by the UK Prospective Diabetes Study: progressive deterioration of glycaemic control and beta cell function irrespective of therapy, be it pharmacological or non-pharmacological [3]. Even the most exciting new drugs, such as dipeptidylpeptidase IV inhibitors or glucagon-like peptide 1 agonists, seem to fail to produce persistent improvements in beta cell function $[4,5]$. On a positive note, the study of Lim et al. in this issue of Diabetologia reminds us that type 2 diabetes and its pathophysiological defects are indeed entirely reversible, at least in the short-term [6].

Lim et al. tested the hypothesis that a sudden, remarkable negative energy balance is a signal that induces a series of metabolic events beyond those expected for the amount of weight lost [6]. Eleven obese patients with type 2

H. Yki-Järvinen $(\bowtie)$

Department of Medicine, University of Helsinki,

Haartmaninkatu 8, Room C426B,

00290 Helsinki, Finland

e-mail: ykijarvi@cc.helsinki.fi diabetes (BMI $33.6 \mathrm{~kg} / \mathrm{m}^{2}, \mathrm{HbA}_{1 \mathrm{c}} 7.4 \%$ [57 $\left.\mathrm{mmol} / \mathrm{mol}\right]$ ) were studied before and after 1,4 and 8 weeks of a $2.5 \mathrm{MJ}$ $(600 \mathrm{kcal}) /$ day liquid formula diet (46\% carbohydrate, $33 \%$ protein, $20 \%$ fat; around $70 \mathrm{~g}$ of carbohydrate per day). The patients had been diabetic for less than 4 years and were treated with oral antihyperglycaemic agents other than glitazones. Hepatic and peripheral insulin sensitivity and beta cell function were assessed using state-of-the-art methods. The triacylglycerol content of the pancreas and liver were measured using proton magnetic resonance spectroscopy imaging ( $\left.{ }^{1} \mathrm{H}-\mathrm{MRS}\right)$. Eight age-, sex- and weight-matched non-diabetic individuals were studied as a control group. At the end of 8 weeks, the patients had lost $15 \mathrm{~kg}(15 \%)$ of their body weight. Their fasting glucose and $\mathrm{HbA}_{1 \mathrm{c}}$ levels became normal and their plasma triacylglycerol levels halved. Liver fat content decreased by $70 \%$, from $12.6 \%$ to $2.9 \%$. Or, put another way, non-alcoholic fatty liver disease disappeared (normal liver fat is $<5.6 \%$ using ${ }^{1} \mathrm{H}-\mathrm{MRS}$ ). Hepatic insulin sensitivity improved, while muscle insulin sensitivity did not change. After only 1 week, liver fat had decreased by $30 \%$, fasting glucose had been normalised and the fasting insulin secretion rate had significantly decreased. Throughout the study the acute insulin response to glucose increased in a continuous manner and was similar to that in the non-diabetic volunteers at 8 weeks. Pancreatic fat content showed an inverse pattern and gradually decreased to normal.

Sudden energy restriction lowers postprandial glucose and insulin concentrations (Fig. 1). The latter triggers, at least if the amount of carbohydrate is sufficiently low $(<60 \mathrm{~g} /$ day $)$, an increase in fasting and postprandial NEFAs as well as ketone bodies [7]. The decrease in insulin can be predicted to decrease liver fat by diverting NEFA flux from lipogenesis to oxidation, although these processes have not 
Fig. 1 Effects of sudden marked energy restriction on glucose and lipid metabolism. Please see the text for a detailed description of putative mechanisms. The yellow circles indicate adipose tissue. F, fasting; FA, fatty acid; NAFLD, nonalcoholic fatty liver disease; PP, postprandial, TG, triacylglycerol

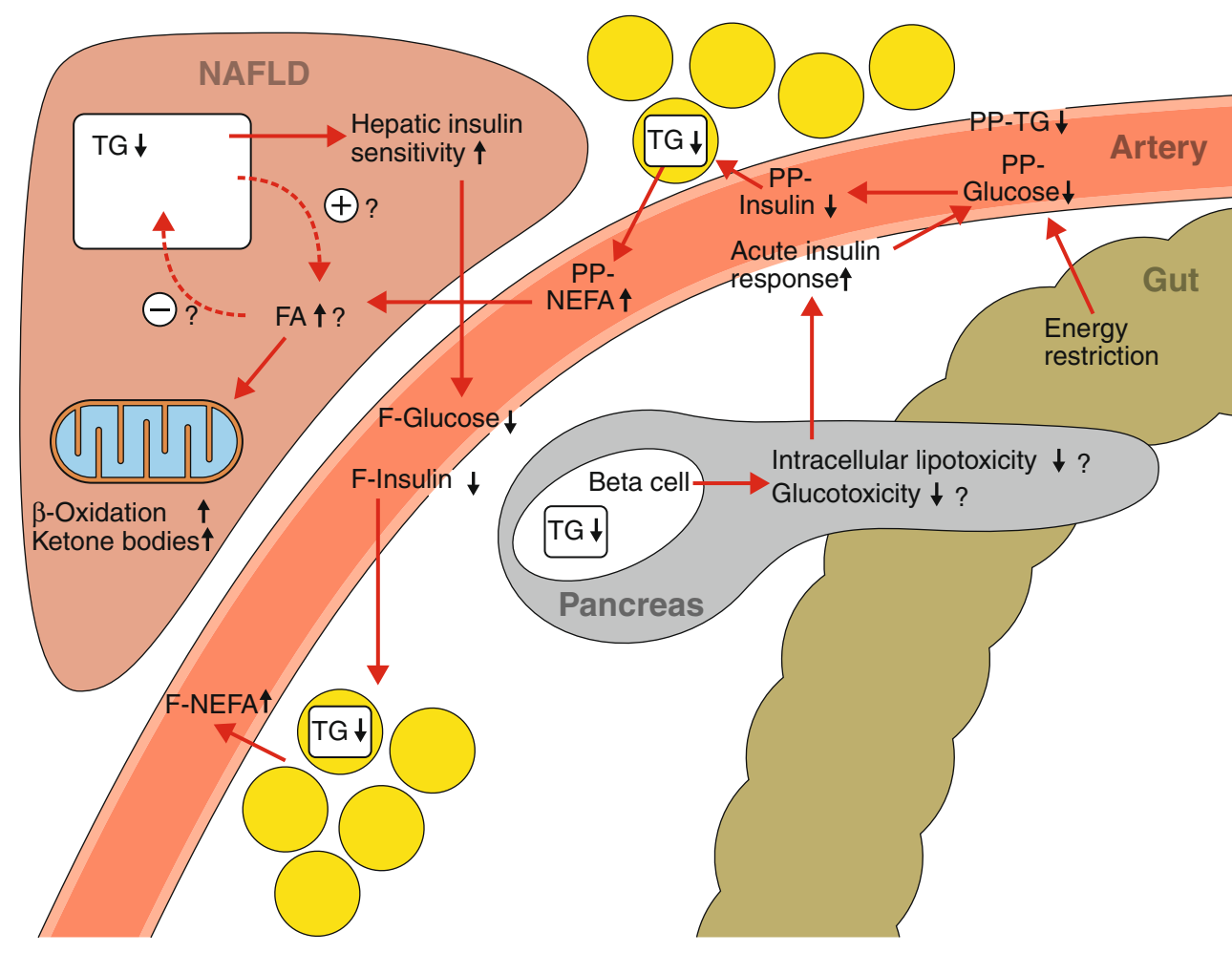

been measured directly in humans [8]. During a 1 week low-carbohydrate diet, the rate of lipolysis both basally and during hyperinsulinaemia increases, although the ability of insulin to suppress lipolysis (i.e. insulin sensitivity of lipolysis) is enhanced [9]. Plasma NEFA levels also increased during the first week and then decreased in the study of Lim et al. The latter is consistent with previous weight loss studies of longer duration, in which NEFA levels remained unchanged or decreased [10, 11]. Regardless of the diet used to induce weight loss, liver fat content decreases and the ability of insulin to suppress hepatic glucose production increases. This diminishes the amount of insulin needed to control hepatic glucose production and helps to control glycaemia [12]. The rapid and dramatic decrease in liver fat $(30 \%$ in 1 week, $3.9 \%$ change in body weight) and improvement in hepatic insulin sensitivity are consistent with several previous studies showing a marked decrease in liver fat in the face of trivial weight loss within a week or two $[8,9,13]$. Negative energy balance also lowers both fasting and postprandial triacylglycerol levels [14] (Fig. 1).

The normalisation of insulin secretory responses to glucose and arginine in the study of Lim et al. [6] is intriguing. How can this finding based on careful study of 11 patients be reconciled with the results of gigantic genome-wide association scan studies in which most of the identified gene variants influence the capacity of beta cells to increase insulin secretion to meet the demands imposed by obesity and insulin resistance? It should be noted that the gene variants identified to date increase the ability to predict type 2 diabetes by only $1 \%$ [15]. Alternatively, perhaps the genes regulating insulin secretion really are important in determining who develops type 2 diabetes but since the beta cell defect is relative, improvements in hepatic insulin sensitivity by weight loss allow restoration of normoglycaemia. A decrease in beta cell volume to below $1.1 \%$ of the total pancreatic volume is associated with a steep increase in plasma glucose and a further decrease in beta cell volume [16]. It is therefore important to establish in future studies the range of initial glycaemia or beta cell mass within which a marked energy deficit can induce remission. Nonetheless, the study of Lim et al. shows that, in patients with established type 2 diabetes (fasting plasma glucose of $9.2 \mathrm{mmol} / \mathrm{l}$ ), a healthy lifestyle can compensate for bad genes - as indeed has been shown for diabetes prevention [17].

Lim et al. [6] also observed a decrease in pancreatic fat in response to weight loss. The measurement of pancreatic fat does not necessarily reflect that inside beta cells. Thus, whether insulin secretion improved because the beta cells became slimmer, glucose concentrations decreased or some other reason remains an open question (Fig. 1).

Can the results obtained by studying 11 type 2 diabetic patients be generalised and used in clinical practice? The study was not underpowered as most pathophysiological defects in type 2 diabetes could be significantly ameliorated. This emphasises how effective the intervention was. Did we learn something new? The repeated measurement of 
several key pathogenic defects is novel and showed that most of the good happened within just one week. We can, thus, use the study as encouragement-'You can get rid of your diabetes in a week if you lose $4 \mathrm{~kg}$.' - instead of just prescribing more pills and injections. Easier said than done. The real questions are: How can we motivate patients and how can we sustain what was achieved within a few weeks for decades? Remission in a week may not be cure for life. How skilled are we as healthcare professionals in helping patients to lose weight and avoid weight regain? Did you ever get any training in such skills? I didn't. During my years in medical school, type 2 diabetes was just 'a bit of sugar in the urine'. I learnt how to write a prescription and have since learnt that what I would need the most is what I know the least: how to help, encourage and support the patient to take control. We need a shift in the paradigm in the early management of type 2 diabetes.

Acknowledgements I thank K. Sevastianova and J. Hyysalo for their constructive and creative comments regarding the manuscript.

Contribution statement HY-J was responsible for the conception, writing and final approval of this article.

Duality of interest The author declares that there is no duality of interest associated with this manuscript.

\section{References}

1. Tuomilehto J, Lindstrom J, Eriksson JG et al (2001) Prevention of type 2 diabetes mellitus by changes in lifestyle among subjects with impaired glucose tolerance. N Engl J Med 344:1343-1350

2. Knowler WC, Fowler SE, Hamman RF et al (2009) 10-year follow-up of diabetes incidence and weight loss in the Diabetes Prevention Program Outcomes Study. Lancet 374:1677-1686

3. U.K. Prospective Diabetes Study Group (1995) UK Prospective Diabetes Study 16. Overview of 6 years' therapy of type II diabetes: a progressive disease. Diabetes 44:1249-1258

4. Bunck M, Cornér A, Eliasson B et al (2011) Effects of exenatide on measures of $\beta$-cell function after 3 years in metformin treated patients with type 2 diabetes. Diabetes Care. doi:10.2337/dc11-0291
5. Foley JE, Bunck MC, Moller-Goede DL et al (2011) Beta cell function following 1 year vildagliptin or placebo treatment and after 12 week washout in drug-naive patients with type 2 diabetes and mild hyperglycaemia: a randomised controlled trial. Diabetologia. doi:10.1007/s00125-011-2167-8

6. Lim EL, Hollingswirth KG, Aribisala BS, Chen MJ, Mathers JC, Taylor R (2011) Reversal of type 2 diabetes: normalisation of beta cell function in association with decreased pancreas and liver triacylglycerol. Diabetologia. doi:10.1007/s00125-0112204-7

7. Hernandez TL, Sutherland JP, Wolfe P et al (2010) Lack of suppression of circulating free fatty acids and hypercholesterolemia during weight loss on a high-fat, low-carbohydrate diet. Am J Clin Nutr 91:578-585

8. Kirk E, Reeds DN, Finck BN, Mayurranjan MS, Klein S (2009) Dietary fat and carbohydrates differentially alter insulin sensitivity during caloric restriction. Gastroenterology 136:1552-1560

9. Sevastianova K, Kotronen A, Gastaldelli A et al (2011) Genetic variation in PNPLA3 (adiponutrin) confers sensitivity to weight loss-induced decrease in liver fat in humans. Am J Clin Nutr 94:104-111

10. Albu JB, Heilbronn LK, Kelley DE et al (2010) Metabolic changes following a 1-year diet and exercise intervention in patients with type 2 diabetes. Diabetes 59:627-633

11. Vitola BE, Deivanayagam S, Stein RI et al (2009) Weight loss reduces liver fat and improves hepatic and skeletal muscle insulin sensitivity in obese adolescents. Obesity (Silver Spring) 17:17441748

12. Kotronen A, Yki-Järvinen H (2008) Fatty liver: a novel component of the metabolic syndrome. Arterioscler Thromb Vasc Biol 28:27-38

13. Colles SL, Dixon JB, Marks P, Strauss BJ, O’Brien PE (2006) Preoperative weight loss with a very-low-energy diet: quantitation of changes in liver and abdominal fat by serial imaging. Am J Clin Nutr 84:304-311

14. Maraki M, Sidossis LS (2010) Effects of energy balance on postprandial triacylglycerol metabolism. Curr Opin Clin Nutr Metab Care 13:608-617

15. Lyssenko V, Jonsson A, Almgren P et al (2008) Clinical risk factors, DNA variants, and the development of type 2 diabetes. N Engl J Med 359:2220-2232

16. Ritzel RA, Butler AE, Rizza RA, Veldhuis JD, Butler PC (2006) Relationship between beta-cell mass and fasting blood glucose concentration in humans. Diabetes Care 29:717-718

17. Hivert MF, Jablonski KA, Perreault L et al (2011) Updated genetic score based on 34 confirmed type 2 diabetes Loci is associated with diabetes incidence and regression to normoglycemia in the diabetes prevention program. Diabetes 60:1340-1348 